\title{
A amplitude axiológica da categoria trabalho: contra o trabalho (estranhado) e pelo trabalho (substancialmente livre)
}

The axiological amplitude of labour: against the (estranged) labour and for the (substantially free) labour.

\section{Bruna da Penha de Mendonça Coelho ${ }^{1}$}

${ }^{1}$ Universidade do Estado do Rio de Janeiro, Rio de Janeiro, Rio de Janeiro, Brasil. E-mail: brunapmcoelho@gmail.com. ORCID: https://orcid.org/0000-0003-4974-1590.

\section{Felipe de Souza Matos ${ }^{2}$}

2 Universidade Federal do Rio de Janeiro, Rio de Janeiro, Rio de Janeiro, Brasil. E-mail: felipematos14@hotmail.com. ORCID: https://orcid.org/0000-0001-9618-5430.

Artigo recebido em 17/01/2020 e aceito em 16/04/2020.

\section{$(\mathrm{cc}) \mathrm{EY}$}

This work is licensed under a Creative Commons Attribution 4.0 International License. 


\section{Resumo}

O artigo objetiva perquirir a amplitude axiológica da categoria trabalho, dada sua relevância para a compreensão dos processos de resistência social contra o estranhamento do trabalho humano. Investiga o conceito ontológico de trabalho, as circunstâncias histórico-sociais que caracterizam o trabalho sob o modo de produção capitalista, além da importância da reivindicação social por um conteúdo emancipatório para o trabalho humano.

Palavras-chave: Trabalho; Estranhamento; Emancipação.

\section{Abstract}

The paper aims to investigate the axiological amplitude of the category called labour, because of its relevance to understand the processes of social resistance against the estranged labour. It investigates the ontological concept of labour, the historical-social circumstances that characterize labour under the capitalist mode of production, as well as the importance of social claim for an emancipatory content for human labour.

Keywords: Labour; Estrangement; Emancipation. 


\section{Introdução}

Não raro são levantadas propostas, mesmo dentro dos estudos críticos e que se pretendem materialistas, de que a superação da barbárie capitalista demanda que abandonemos a categoria trabalho enquanto chave de compreensão sociológica da realidade social. Entre os argumentos comumente apresentados, repousa, de um lado, a crença de tipo habermasiana em uma suposta perda da centralidade social do trabalho no chamado capitalismo tardio'; de outro, a crença de que o conceito de trabalho se resume ao que conhecemos como tal sob o modo de produção capitalista (o trabalho estranhado).

Quanto à primeira crença, parece-nos que as amplas evidências empíricas dão conta de que não se verifica uma retração do trabalho e da figura dos trabalhadores na sociedade contemporânea - muito pelo contrário. ${ }^{2}$ Além dos dados empíricos que indicam o crescimento da classe trabalhadora em todo o mundo, encontram-se subsistentes fundamentos teóricos no sentido da intensificação do trabalho pela complexificação tecnológica (DAL ROSSO, 2008), da centralidade axiológica do trabalho (MARX, 2008) e das íntimas relações entre capital financeiro e capital produtivo (FONTES, 2010, pp. 22/3; MARX, 1985/6).

Quanto à segunda, parece-nos que desconsidera todas as bases valorativas do que se constitui, historicamente, enquanto trabalho fundador de sociabilidade humana. Ignora que o que caracteriza o capitalismo é a conversão da força de trabalho em mercadoria e a extração de valor a partir de sua usurpação, e não uma espécie de invenção social da categoria trabalho em si (que é histórica e axiologicamente anterior ao capital - e, por isso mesmo, central para o processo revolucionário de superação deste modo de produção). Compreender a complexidade dessa dinâmica requer, portanto, que se recobre a amplitude valorativa do próprio conceito de trabalho. Não é outro o objetivo central deste artigo.

Para tanto, propõe-se o cotejo entre a amplitude deste conceito e a retomada da gênese do trabalho sujeitado ao interesse do capital, a fim de perquirir as particularidades sociológicas deste modo de produção (que, como particularidades que são, podem ser historicamente modificadas). À luz do materialismo histórico marxista

\footnotetext{
${ }^{1}$ Cf., dentre outros, HABERMAS, 1987; OFFE, 1986. Para uma abordagem crítica: ANTUNES, 2006.

${ }^{2}$ Cf., dentre outros, os dados apresentados em PRIEB, 2012.
} 
(MARX \& ENGELS, 2007), procura-se, a partir da introdução de conceitos essenciais, entender o processo que culmina na predominância da atual concepção do trabalho calcado na essencialidade da subordinação e do estranhamento. Afinal, é impossível analisar a contemporaneidade sem dimensioná-la na progressão dialética do homem e da sociedade. As bases reais e materiais de existência (e de seus conflitos) não são dadas, nem estáticas, mas construídas e alteradas historicamente pelos seres sociais nos processos relacionais.

Ressalte-se que não se trata de uma retrospectiva histórica linear. O que se persegue é uma exploração de conceitos ontológicos ligados ao fenômeno laboral sempre entendido no devir temporal. Longe de um historicismo narrativo, o processo histórico será o suporte de aplicação e materialidade dos fundamentos.

Considerado como entidade na historicidade (assim como tudo), pensar na substancialidade do trabalho preconiza o retorno a suas raízes. As contradições em embate no duelo social ao longo da história imprimem em cada nova categoria a marca desse passado dual. Dessa forma, olhar para o passado é ao mesmo tempo enxergar fragmentos elementares do presente. Nas palavras de György Lukács: "ao contrário: a continuidade na persistência é, enquanto princípio de ser dos complexos em movimento, indício de tendências ontológicas para a historicidade como princípio do próprio ser." (LUKÁCS, 2012, p. 79)

É no conceito da suprassunção hegeliana (Aufhebun) que tal paradigma se funda. Para além da dureza da dialética clássica, Hegel propõe enxergar o devir histórico desprendido de suas manifestações imediatistas. Os fenômenos devem ser compreendidos em sua dimensão na totalidade; gestados nos conflitos, em negações que de forma alguma se apagam. Na metáfora explicativa do filósofo:

O botão desaparece no desabrochar da flor, e poderia dizer-se que a flor $\mathrm{o}$ refuta; do mesmo modo que o fruto faz a flor parecer um falso ser-aí da planta, pondo-se como sua verdade em lugar da flor: essas formas não só se distinguem, mas também se repelem como incompatíveis entre si. Porém, ao mesmo tempo, sua natureza fluida faz delas momentos da unidade orgânica, na qual, longe de se contradizerem, todos são igualmente necessários. E essa igual necessidade que constitui unicamente a vida do todo (HEGEL, 2014, p. 22).

Entretanto, o marxismo inverte a dialética hegeliana do campo idealista em que uma razão universal determinaria a realidade mundana. Marx retira as categorias de Ideia ou Espírito como condutores dessa abstração e propõe uma dialética 
materialista, calcada nas observações e representações da realidade. Esse movimento do vir-a-ser hegeliano é valorizado por Marx no sentido de conferir à dialética um papel mais dinâmico e complexo, atuando como motor da história. Apesar de destacar a importância do devir suprassuntivo, esse deslocamento do foco de aplicabilidade feito pelo materialismo histórico é metodologicamente essencial para compreender suas formulações ontológicas. É a partir da metodologia basilar do materialismo histórico dialético, portanto, que se propõe aqui uma análise crítica acerca da amplitude valorativa da categoria trabalho, a fim de compreender sua relevância teórica e prática.

Tendo em vista esse objetivo, o artigo começa por perquirir o conceito ontológico de trabalho e suas relações com a noção de atividade vital consciente e com a fundação da sociabilidade humana. Na sequência, investiga as circunstâncias históricosociais que caracterizam o trabalho sob o modo de produção capitalista, com especial atenção para a configuração da força de trabalho como mercadoria e para o processo de estranhamento do trabalho humano. Por fim, empreende reflexões sobre a fundamentalidade de não se abrir mão da reivindicação por um conteúdo social emancipatório para o trabalho humano.

\section{Trabalho, atividade vital consciente e ser social.}

Percorrer a história do trabalho é necessariamente defrontar-se com a formação do homem como espécie animal social. No pensamento marxista, a potência e realização da atividade de trabalho criativo humano é marco inicial ontológico na compreensão de sua existência. Todavia, esse humano que trabalha não brotou espontaneamente. $\mathrm{Na}$ análise desse percurso temporal de desenvolvimento, propõe-se a diferenciação das formas do ser em: ser inorgânico, ser orgânico e ser social. A capacidade reprodutiva é o marco diferenciador entre o inorgânico e o orgânico.

O ser orgânico, relativamente mais complexo, finalisticamente intenta reproduzir a si. A intenção de mantença genética, perpetuação contrasta com o tornarse outro observado nos seres inorgânicos. Nessa escalada, como ressaltado na leitura de Lukács (2012), a transição entre o ser orgânico e o ser social se dá pela atividade criativa essencialmente humana.

Tal como a reprodução do mesmo se constitui em momento predominante do salto ontológico que deu origem à vida, a reprodução do novo, através 
da transformação conscientemente orientada do real, se constitui no momento predominante do salto que marca a gênese do ser social. (LESSA, 2015, p. 20)

A construção desse trabalhar envolve precipuamente o processo consciente de instrumentalizar/mediar a relação do homem com o ambiente natural. Essa tomada de consciência da potencialidade inovadora humana exerce uma dupla transformação: no âmbito interno e externo, configurando um salto ontológico. A possibilidade de idealização e execução configura a ruptura com as limitações do ser orgânico que apenas intuitivamente copia.

Chega-se, portanto, ao conceito axiológico basilar de trabalho, que pode ser extraído, primeira e fundamentalmente, dos Manuscritos Econômico-Filosóficos de Marx: trabalho é a atividade vital consciente com predeterminação de fins - e que caracteriza o homem enquanto tal. "O homem [...] tem atividade vital consciente. [...] A atividade vital consciente distingue o homem imediatamente da atividade vital animal. Justamente, [e] só por isso, ele é um ser genérico. [...] Eis por que a sua atividade é atividade livre" (MARX, 2008, p. 84).

É justamente a amplitude valorativa do conceito que nos permite entender a particularidade histórica do estranhamento do trabalho operado pelo modo de produção capitalista, que será abordado de forma mais detida no próximo item deste artigo. Reduzir o conceito de trabalho à forma peculiar que assume no capitalismo, sem compreender sua dimensão primeira e central enquanto atividade vital consciente, retrai a potencialidade da crítica ao estranhamento do trabalho e coloca o debate em plano superficial.

Se trabalho é toda atividade vital consciente com determinação prévia de fins (sendo, portanto, o que caracteriza o ser social como tal), não é difícil perceber sua amplitude e, consequentemente, sua centralidade axiológica na compreensão das relações sociais. Aos que argumentam que esta conceituação seria inútil justamente por sua extensão, responde-se que o objetivo de um conceito (delimitar um fenômeno social no mundo) não deve ser lido em sentido reducionista.

Delimitar um fenômeno não significa colocá-lo em uma amarra teórica ou confundi-lo com representações individualizáveis, mas antes caracterizar as especificidades sociais que podem ser associadas ao conceito. A consciência e a consequente capacidade de estabelecer previamente as finalidades da atividade vital a 
ser empreendida delimitam, portanto, o conteúdo social daquilo que se pode caracterizar como trabalho verdadeiramente livre. Cumpre-se, portanto, a função que se espera de um conceito.

Subjetivamente, o trabalho proporciona ao ser social desenvolvimento de suas capacidades, experimentação, acúmulo de conhecimento. No trabalho, o homem confirma o seu ser e seu saber. Essa jornada de autodescoberta encontra no produto do trabalho a materialização de uma idealização prévia. Além de anterior, essa mentalidade é teleológica no sentido de que carrega um propósito utilitário.

Como formador de valores de uso, como trabalho útil, o trabalho é desse modo, uma condição de existência do homem independentemente de todas as formas sociais, uma eterna necessidade natural de mediar o metabolismo entre homem e natureza, portanto, a vida humana (MARX, 2011, p. 167).

Contudo, a relação entre homem e natureza não é dicotômica, tampouco hierarquizada. O homem veio, é e para sempre será natureza. Assim como o trabalho que inexoravelmente, em seu momento primordial, envolve a modificação do natural e carregará eternamente essa herança em seus produtos. Por mais desenvolvida que seja a sociabilidade humana, nunca será esvaída a ancestralidade presente da natureza.

Em outras palavras, o salto qualitativo representado pela passagem do inorgânico à vida tem um duplo efeito. Por um lado, assinala a gênese de uma nova esfera de ser qualitativamente distinta da anterior. Por outro lado, instaura na natureza uma processualidade cuja continuidade é dada por um processo reprodutivo que apenas pode se efetivar tendo por base a natureza inorgânica. Neste sentido, se há uma irredutibilidade ontológica das leis da vida às da esfera inorgânica, não menos verdadeiro é que a esfera pode surgir e se reproduzir tendo por base o mundo inorgânico (LESSA, 1992).

Ressalte-se que não se trata de um darwinismo social, de leis naturais inescapáveis a conduzir a experiência humana. O tempero social estará sempre e cada vez mais complexificando esse relacionamento. As necessidades naturais do homem somente se realizam em sociedade. Mais uma vez, o raciocínio dialético aplicado sintetiza sem excluir.

Nesse escopo, o dinamismo observado é a constante superação das necessidades naturais, orgânicas pelas relações sociais complexas. Por óbvio, não se trata de um processo de anulação da chamada barreira natural. Tal consideração é impossível no momento em que o orgânico é basilar e insuperável. 
Entra aí a centralidade do pôr teleológico que, na tomada de consciência e atuação prática, possibilita ao ser social a intromissão nas cadeias causais da natureza. Essa interferência criativa é embebida completamente no caldo das mediações sociais. Para além de uma modificação interna, o trabalho em sua externalização será compartilhado, enxergado numa dimensão coletiva.

Caracteriza-se aí o fenômeno da objetivação. O produto criativo desprende-se de seu criador e torna-se objeto social. Não só o produto, mas também as técnicas produtivas são coletivizadas. Verifica-se o processo de generidade do trabalhar enquanto fundador ontológico do ser social. As categorias sociais genéricas posteriores advêm dessa raiz. É na alienação da exteriorização da consciência criativa prévia do sujeito-autor que se institui o salto ontológico (LUKÁCS, 2012).

Ao conjunto dessas objetivações estaria reservado o conceito de práxis. Para Marx, o homem é antes de tudo um ser prático e social. Este caráter da humanidade é exemplificado paradigmaticamente pelo trabalho. 0 trabalho não pode ser encarado, então, como uma penitência, uma obrigação, mas, sim, uma objetivação privilegiada que garante a condição humana em sua essencialidade (MARX, 2011, p. 161).

Sobre a questão linguística que envolve a palavra trabalho, anota Suzana Albornoz que, não raro, o termo encerra múltiplas significações em diversos idiomas (ALBORNOZ, 1988, p. 8). Na língua portuguesa não é diferente, sendo utilizado, inclusive, para designar a ideia de fardo ou aflição. Albornoz $(1988$, p. 12) aponta que esse fenômeno pode ser explicado pela tese de que a origem etimológica adviria do latim tripalium, expressão que indica a ferramenta de três pontas utilizada na lavoura e também como instrumento de tortura.

Interessante também ressaltar que a tradição judaico-cristã, que marca forte influência na formação da cultura ocidental (incluindo a nossa), fincou-se na ideia, à semelhança do pensamento filosófico grego, de que a atividade contemplativa seria mais honrada que as demais (ALBORNOZ, 1988, p. 52). ${ }^{3}$ Já em Gênesis, o trabalho é apresentado como uma punição ao pecado original de Adão e Eva: "Com o suor do seu rosto você comerá o seu pão, até que volte a terra, visto que dela foi tirado; porque você é pó, e ao pó voltará". ${ }^{4}$

\footnotetext{
${ }^{3}$ Sobre os novos contornos entre trabalho e religião a partir da reforma protestante, cf. ALBORNOZ, 1988, p. 53 e ss.

${ }^{4}$ Bíblia Sagrada, Gênesis 3, v. 19.
} 
O desenvolvimento do capitalismo industrial e a suposta valorização burguesa ao conceito de trabalho, cuja finalidade era (e é) empurrar a força de trabalho ao mercado, também não resolvem o dilema da utilização deste termo no imaginário social. Os discursos ideológicos hegemônicos vendem a ideia de que o trabalho dignifica o homem, mas se referem propriamente a uma expressão específica deste trabalho: o trabalho estranhado e propiciador da autovalorização do capital. Se por um lado esta ideologia é incutida nas relações sociais, por outro não é capaz de blindar totalmente a percepção coletiva de que este trabalho impinge níveis de sofrimento. Como algo tão sofrido pode dignificar?

Como se pode observar, são muitas as contingências histórico-sociais que envolvem o arcabouço discursivo em torno do conceito de trabalho e suas respectivas disputas. Longe de pugnar por uma valorização ingênua deste conceito, o que se confundiria com a ocultação burguesa da exploração do trabalho, o objetivo deste artigo é repensar a amplitude axiológica deste termo a partir de uma perspectiva crítica e materialista.

Válido apontar, ainda que de forma breve e limitada, a controvérsia levantada por Hannah Arendt, no terceiro capítulo de $A$ condição humana, sobre a concepção de trabalho na obra de Marx. ${ }^{5}$ Arendt (2007, pp. 116 e ss.) sustenta que o autor teria engendrado uma contradição ao definir o trabalho, por um lado, como uma necessidade ditada permanentemente pela natureza (sendo através do trabalho que se realiza a humanidade), e, por outro, ao afirmar que o propósito da revolução seria emancipar o homem do trabalho, para que pudesse ser verdadeiramente livre.

Esta suposta contradição, porém, é unicamente aparente. Se tomarmos em conta a obra de Marx como um todo e, sobretudo, se nos ativermos à extensão teóricoprática do conceito de trabalho, observaremos que, na proposta de emancipar o homem do trabalho para que ele possa ser substancialmente livre, Marx se refere especificamente ao trabalho estranhado posto a serviço da autovalorização do capital. Isto é, refere-se a apenas um dos possíveis sentidos de trabalho. A reivindicação do conteúdo social emancipatório (isto é, enquanto atividade vital consciente e materialmente livre) da categoria trabalho é, portanto, o próprio veículo de superação da barbárie ditada pelo estranhamento, pela exploração e pela expropriação do trabalho. Daí também o desvelamento da aparente contradição do título deste artigo.

${ }^{5}$ Para maior aprofundamento, cf. MAGALHÃES, 2010. 
Esta busca pelo conteúdo social emancipatório do conceito de trabalho só pode ser verdadeiramente emancipatória se comprometida com a práxis, com a transformação do mundo, com o desfazimento material e histórico das relações capitalistas que, em seu cerne, demandam a subjugação e a usurpação do trabalho humano e do trabalhador. Nas palavras de Paulo Freire:

Não é no silêncio que os homens se fazem, mas na palavra, no trabalho, na ação-reflexão. Mas, se dizer a palavra verdadeira, que é trabalho, que é práxis, é transformar o mundo, dizer a palavra não é privilégio de alguns homens, mas direito de todos os homens (FREIRE, 2019, pp. 108/9).

E o que se entende por emancipação aqui? Por certo, não nos referimos a uma perspectiva liberal individualizada do termo, que se daria a despeito da radical alteração das desigualdades sociais materiais. Pelo contrário, adota-se aqui uma noção materialista de emancipação:

[...] desejamos desenvolver a tese marxista que coloca a emancipação humana como conquista histórica da humanidade quando liberta-se da injunção da produção da existência, desenvolvendo forças produtivas que Ihe permitem reduzir a injunção da relação com a natureza possibilitando a expansão das potencialidades da espécie (ser universal) e indivíduo (subjetividade). (PEIXOTO, 2013, p. 7).

\section{A particularidade histórica do trabalho sob o modo de produção capitalista}

\subsection{A transfiguração da força de trabalho em mercadoria}

Qualquer produto do trabalho humano intrinsicamente possui um valor de uso, já que se materializa de um propósito teleológico prévio. Manejando as propriedades do objeto, os artefatos são produzidos e compartilhados socialmente na sua essência de utilidade (MARX, 2011, p. 172). No raciocínio marxista, a utilidade só é realizada e, portanto, aferida na externalidade do objeto. Somente no uso, consumo do produto do trabalho é que se realiza a sua finalidade. Essa acepção preconiza que o valor de uso não é uma instância abstrata, mas estritamente conectada ao corpo, externalidade posta na humanidade.

Tomando o produto do trabalho em sua forma natural, o seu valor de uso estará vinculado à força do trabalho humano teleológico. Toda a técnica criativa, inovadora da manipulação produtiva estará na essência do artefato final. Destaque-se que essa utilidade é mutante, desenvolvendo-se e relacionando-se no exterior social. 
Esse ser social possui como característica ontológica a perspectiva relacional. Nesse âmbito, surge a categoria mercadoria, enxergando o produto do trabalho em seu valor de uso também para o outro. O humano social se relaciona, troca experiências, saberes, produtos. Essas transferências produtivas dar-se-ão, principalmente, por meio da troca entre mercadorias.

Trocar uma coisa pela outra envolve uma relação de correspondência de valores. Marx enxerga nessa permuta dois polos: uma forma relativa e outra equivalente (MARX, 2011, p. 183). Essa configuração envolve um produto (considerado em sua corporeidade) que relativamente é dado como correspondente a outro.

Esse outro, em seu lugar comparativo de equivalente, é completamente abstraído de seu valor de uso (de sua externalidade), apenas servindo como um elemento de comparação viabilizador da permuta. Nas palavras de Marx: "o valor de uso se torna a forma de manifestação de seu contrário, do valor" (MARX, 2011, p. 184). Para ser considerada em sua forma-valor, a mercadoria deve sempre ser posta em confronto com outra.

Essa afirmação permite a inferência de que a forma de valor de uma mercadoria não é uma propriedade natural, orgânica. Pelo contrário, só se manifesta e é entendida no mar das relações histórico-sociais. Sendo assim, o corpo das mercadorias submetidas à troca é apartado, restando nessa relação a sua forma de valor. Mas importante não se olvidar de que, em essência, esse intercâmbio tem como motivação o gozo de uma utilidade.

$\mathrm{Na}$ execução dessas permutas, é necessária uma grandeza para instrumentalizar tais relações. O embate entre as formas de valor das mercadorias impõe uma unidade, uma uniformização. Marx assevera que essa unidade de medição será a quantidade de trabalho humano empregado na produção da mercadoria. Quantidade essa medida em grandeza temporal (minutos, horas, dias,...), socialmente valorada (MARX, 2011, p. 160).

Ao parametrizar o valor de troca pela fração de trabalho humano empenhado, Marx destaca a condição essencialmente social na qual essas trocas estão fundamentadas. Desmistificam-se as operações que, rotineiramente reiteradas, acabam tornando-se naturalmente afastadas de suas raízes. Marx expõe e não nos deixa esquecer que toda troca mercantil envolve um intermediar da dedicação e tempo útil humano. Esse liame social só pode acontecer ao utilizar-se do trabalho numa dimensão 
abstrata, de forma genérica. O que se entende por soma de atividade humana no produto é chamado pelo pensador de "geleia de trabalho humano" (MARX, 2011, p. 161).

Da objetivação da concretude do trabalho, chega-se a um denominador comum que viabiliza a comensurabilidade e, consequente, troca entre mercadorias. Esse rejeitar do trabalho individual teleológico foi oportuno para a dinâmica cambial. Contudo, por vezes (convenientemente) se escondem nesse movimento os seus matizes mais relevantes:

Todo trabalho é, por um lado, dispêndio de força humana de trabalho em sentido fisiológico, e graças a essa sua propriedade de trabalho humano igual ou abstrato ele gera o valor das mercadorias. Por outro lado, todo trabalho é dispêndio de força humana de trabalho numa forma específica, determinada à realização de um fim, e, nessa qualidade de trabalho concreto e útil, ele produz valores de uso (MARX, 2011, p. 172).

Nessa abstração da utilidade do trabalho individual, seria a mercantilização um mal necessário? Em verdade, não se trata de bem ou mal, mas de uma contingência dos arranjos sociais complexos que se deram na experiência histórica. O que se propõe é uma compreensão mais ampla e crítica da essência (não no sentido metafísico, mas no sentido material e histórico) implicada na troca de mercadorias. É iluminar o percurso produtivo e a circulação desses artefatos, intentando afastar-se da oportunista lógica capitalista de mascarar e inverter os papéis de condução da máquina econômica.

Marx utiliza-se da expressão fetichismo da mercadoria para analisar essa cisão. O fenômeno da permuta e sua massificação gera no trabalhador um novo propósito de sua atividade, não só para autobenefício. Ao generalizar trabalhos desiguais, o valor de troca influenciará a produção, vista na sua objetificação social (MARX, 2011, p. 160).

No transcorrer histórico, as relações capitalistas reiteradas se massificam e, na mesma medida, são naturalizadas. A proposta marxiana, em seu fim, ilumina esse intrincado relacionamento, apostando na racionalidade para compreender as práticas do capital em suas formas reais. A partir de uma estrutura lógica simples, denudam-se questões elementares: quem produz, o que produz, como vamos trocar?

Ressalte-se que, para a lógica desse sistema de trocas funcionar de forma pretensamente leal, adota-se como pressuposto a igualdade entre as forças de trabalho na sua generidade. Já em seu início, o capitalismo parte de fundamentos que, em simples observação prática, não se efetivam na realidade social. 
Analisando pela abordagem marxista, compreender o fenômeno da atribuição de valor e operacionalização de trocas mercantis é de grande relevância social. Essa dinâmica revela escolhas, prioridades postas em (pela) sociedade que variam de acordo com a realidade histórica. Submetidas ao interesse do capital, analisar a divisão social do trabalho e sua base de subordinação envolve necessariamente uma arqueologia das práticas históricas que culminaram nesse modelo.

Desde seu encetamento, os pensadores liberais já se utilizam da estratégia de reificação das instâncias mercantis ("a mão invisível do mercado") que harmonizariam os interesses sociais dos indivíduos "livres":

Os ricos consomem pouco mais do que os pobres e, apesar de seu egoísmo e de sua rapacidade naturais, embora desejem apenas sua própria conveniência, embora o único fim ao qual destinem as labutas de todos os milhares que empregam seja a gratificação de seus próprios desejos vãos e insaciáveis, eles dividem com os pobres o fruto de todos os seus melhoramentos. São levados por uma mão invisível a fazer quase a mesma distribuição do que é necessário à vida que teria sido feita se a terra tivesse sido dividida em porções iguais entre todos os seus habitantes, e assim, sem o pretender, sem o saber, promovem o interesse da sociedade (SMITH, 2002, p. 129).

Exemplarmente, o trecho acima revela a inversão na qual a forma de produção domina seus produtores. A mercadoria e sua fetichização instituem o empoderamento das leis de mercado burguesas que dominam e costuram a teia das relações de trabalho. Nessa dinâmica de coisificação, cristaliza-se um imaginário social inescapável para que a desigualdade (inerente e essencial para a reprodução capitalista) mantenha "cada um no seu quadrado", gozando sua pretensa "liberdade".

Ao dinheiro, coube o papel de se constituir enquanto equivalente universal, o que acaba assimilado como sua propriedade útil: "Desempenhar o papel do equivalente universal no mundo das mercadorias torna-se sua função especificamente social e, assim, seu monopólio social" (MARX, 2011, p. 202). O fenômeno de atribuição de valor é subvertido na forma-dinheiro. A própria substância do produto é vinculada a seu valor finalístico na troca. Não se abandonam suas demais propriedades (a exemplo do dinheiro como metal precioso), mas, em essência finalística, o dinheiro é socialmente formatado para a prática mercantil.

Sendo assim, o produto monetário foi feito para e só faz sentido nas trocas complexas sociais. Inicialmente Marx analisa essa dinâmica como uma circulação simples de mercadoria. O movimento envolve uma mercadoria que é vendida por 
determinado valor que é materializado pelo dinheiro. Dinheiro esse com que o antes vendedor agora irá comprar a mercadoria útil para sua subsistência. O modelo, considerando " $M$ " mercadoria e " $D$ " dinheiro, é o seguinte: M-D-M (MARX, 2011, p. 243).

Como acima exposto, a moeda será o intermediário, adstrita em seu caráter instrumental. O que se intenta é vender um valor de uso para adquirir outra utilidade. Em pureza, essa circulação envolve uma troca de equivalentes. Previamente explanada, a equação relativo-equivalente da permuta não perde sua utilidade.

Entendida como performance em sociedade, essa circulação encerra papéis econômico-sociais perpetuados e necessariamente cambiáveis de vendedor de mercadoria, e possuidor de dinheiro que precisa comprar utilidades. Esse ciclo é reiterado na história da economia política, mas a constatação essencial e inaugural marxiana é de que a mera circulação simples não cria valor nenhum.

Aqui se encontra o ponto nodal para compreensão da engrenagem capitalista. Marx demonstra que a transformação do dinheiro em capital abrange uma circulação diferenciada. Ela acontece segundo a fórmula: D-M-D. De maneira simplificada, um detentor de dinheiro compra certas mercadorias úteis e as aliena com a finalidade de obter novamente moeda.

Observa-se que, peculiarmente, a finalidade torna-se o dinheiro pelo dinheiro que perde seu mero caráter instrumental. Entretanto, considerando que há equivalência nas trocas mercantis, aparentemente há uma disfuncionalidade. Como o dinheiro tem em sua única utilidade a universalidade viabilizadora de troca, a simples destinação inicial de dinheiro para auferir a mesma quantidade monetária não traz benefício nenhum.

Contudo, o pôr teleológico produtivo original é deturpado. Como numa trapaça às regras históricas do jogo social das permutas, a circulação capitalista só faz sentido com a quebra da equivalência, o valor final deve ser maior que o inicialmente empregado, deve ser um mais-valor. Aqui jaz o conceito de lucro tão caro ao capitalista (MARX, 2011, p. 296).

Nesse escopo, a circulação do capital envolve um refluxo do dinheiro e esse afastamento do valor-utilidade gera incontáveis problemas. $O$ valor de troca é reificado como propósito em si que movimenta a intencionalidade social. As demandas de 
subsistência, pela utilidade dos produtos, por óbvio permanecem. Entretanto, a obtenção do lucro, sua reprodução, acumulação cristalizam-se como propósito maior.

Uma pergunta fundamental surge nesse momento: como o capitalista transforma essa mercadoria intermediária que alienará em um dinheiro maior do que o empregado na sua compra? Como exposto por Marx, a mera circulação de valor não gera lucro, o mais-valor tem que vir do consumo de uma utilidade que proporcione essa condição peculiar, esse desvio produtivo.

A ideia é encontrar um consumo que ao mesmo tempo seja fonte de valor. Um produto em que, na fruição de sua utilidade, consiga-se manipular o valor gerado, escapando da mera troca de equivalentes. Já que o valor da mercadoria tem como parâmetro a quantidade de trabalho, explorar a força de trabalho é a alternativa perfeita. Apropria-se do fundamento que estabelece valor às mercadorias para manipular a atribuição valorativa e auferir o lucro.

A mudança tem, portanto, de ocorrer na mercadoria que é comprada no primeiro ato $D-M$, porém não em seu valor, pois equivalentes são trocados e a mercadoria é paga pelo seu valor pleno. Desse modo, a mudança só pode provir de seu valor de uso como tal, isto é, de seu consumo. Para poder extrair valor do consumo de uma mercadoria, nosso possuidor de dinheiro teria de ter a sorte de descobrir no mercado, no interior da esfera da circulação, uma mercadoria cujo próprio valor de uso possuísse a característica peculiar de ser fonte de valor, cujo próprio consumo fosse, portanto, objetivação de trabalho e, por conseguinte, criação de valor. E o possuidor de dinheiro encontra no mercado uma tal mercadoria específica: a capacidade de trabalho, ou força de trabalho (MARX, 2011, p. 312).

Eis o ponto nodal do funcionamento do capitalismo, sua autovalorização a partir da extração de valor e mais-valor da força de trabalho. Fundamental para sua reprodução a transfiguração da força de trabalho em mercadoria: é esta a particularidade histórica que recai sobre o processo laborativo sob o modo de produção capitalista. E mais: uma mercadoria de tipo especial, capaz de gerar valor, vez que o trabalhador labora mais que o tempo de trabalho socialmente necessário para reproduzir sua própria energia vital.

A subversão de finalidade preconizada pela circulação do capital pressupõe algumas condições para aproveitar-se do consumo da força de trabalho. Entretanto, para haver consumo, alguém precisa vender algo que é de sua propriedade. Sendo assim, o capitalismo necessita de que o trabalhador tenha plena disposição de seu corpo, de seu tempo para negociá-lo. 
Em outro parâmetro, a comercialização de sua força de trabalho precisa ser a única alternativa desse humano para suprir suas necessidades materiais. Todavia, vender sua força de trabalho é vender seu bem mais essencial, dispor do seu corpo. Trata-se de manter seres "livres" para serem parcialmente subordinados. Sustentar essa dualidade funcionando de forma lucrativa requer prévios e permanentes processos expropriatórios abertamente violentos de separação de trabalhadores e seus meios de produção ${ }^{6}$, além da constante abstração de igualdade operada através da sutileza da ocultação dos conflitos, da desorientação e da naturalização das assimetrias sociais.

N’O Capital, a exposição do sistema capitalista enquanto totalidade concreta - síntese de muitas determinações - revela que as condições de possibilidade da confirmação do capital como princípio onímodo de síntese social são o desaparecimento da liberdade substancial do plano do discurso explícito - ao mesmo tempo em que se mantém a aparência de uma liberdade abstrata - e a consequente efetivação da não-liberdade. (OLIVEIRA, 1998, p. 190)

E para desencorajar os que ousarem subverter seu papel social como massa de manobra operária, impossibilita-se o acesso voluntário aos meios de produção necessários para realizar o seu trabalho útil. Num locus mais profundo, é preciso subjugar a existência do trabalhador para que não tenha posse de utilidades promotoras de autossubsistência e, consequentemente, ausência de um caminho diferente do viver.

Para transformar dinheiro em capital, o possuidor de dinheiro tem, portanto, de encontrar no mercado de mercadorias o trabalhador livre, e livre em dois sentidos: de ser uma pessoa livre, que dispõe de sua força de trabalho como sua mercadoria, e de, por outro lado, ser alguém que não tem outra mercadoria para vender, livre e solto, carecendo absolutamente de todas as coisas necessárias à realização de sua força de trabalho (MARX, 2011, p. 314).

A lógica capitalista opera nos níveis mais essenciais do indivíduo no momento que rompe com o livre trânsito do trabalho teleológico. Essa cisão, compreendida no movimento histórico, não aconteceu de forma harmônica, revelando-se num projeto paulatino de submissão de classes. O lucro é gestado na subordinação, o que sempre envolverá algum nível de violência (seja ela explícita ou velada).

${ }^{6}$ Cf., sobretudo, o capítulo 24 de MARX, 2011. 


\subsection{Estranhamento: o desmantelamento da essencialidade humana}

De início, vale ressaltar que, não obstante os termos estranhamento e alienação sejam, com relativa frequência, encontrados na literatura especializada como sinônimos, preferimos aqui nos concentrar no primeiro termo para tratar, especificamente, da questão do trabalho. Essa preferência se deve ao fato de que o termo alienação tende a apresentar maior amplitude, referindo-se muitas vezes à problemática da exteriorização e das produções de sociabilidade, enquanto a expressão estranhamento diz respeito ao termo que caracteriza "as insuficiências de realização do gênero humano decorrentes das formas históricas de apropriação do trabalho, incluindo a própria personalidade humana, assim como as condições objetivas engendradas pela produção e reprodução do homem." (RANIERI, 2006, p. 1)

Desde seu princípio, paulatina e historicamente, a sobrelevação do capital como condutor finalístico econômico-social determinou um processo de mudança de mediação interindividual. Da transformação produtiva e criativa de elementos naturais, o homem e seu trabalhar útil organizam-se como ser numa sociedade. No decorrer temporal, complexificam-se as trocas sociais, entretanto, finalisticamente, o parâmetro da utilidade ainda continua como propósito na generalidade. Nesse estágio, observa-se a economia num nível mais simples, mais puro. A utilização de recursos escassos requer uma racionalidade posta na divisão social do trabalho baseada em critérios de certa forma mais orgânicos; como numa conciliação participativa de interesses sociais.

Ricardo Antunes conceitua a dinâmica acima como "funções primárias de mediações, estabelecidas entre eles (humanos) e no intercâmbio e interação com a natureza, dadas pela ontologia singularmente humana do trabalho" (ANTUNES, 2009, p. 22). Nessa esteira, observa o sociólogo que, para o funcionamento e propagação dessa engrenagem econômica, não há o pressuposto de dominação hierárquica. Mas a sujeição ao capital abarcou a reprodução humana, implementando uma nova ordem de propósito social. Trata-se das mediações de segunda ordem, assim denominadas por Antunes, que ressalta a pretensão totalizante da base capitalista. Ela atuará nas mais diversas dimensões da vida, mediando relacionamentos muito além de uma circunscrição mercadológica.

$\mathrm{O}$ advento dessa segunda ordem de mediações corresponde a um período específico da história humana, que acabou por afetar profundamente a funcionalidade das mediações de primeira ordem ao introduzir elementos 
fetichizadores e alienantes de controle social metabólico (idem:139-140). Isso porque "a constituição do sistema de capital é idêntica à emergência de suas mediações de segunda ordem [...]". (ANTUNES, 2009, p. 23)

Autocentrado no propósito de maximização do lucro, o capital dominante efetua uma disrupção do relacionamento produção e consumo. A essência do consumir para suprir uma necessidade humana é afastada, fetichizando a troca estéril como um fim em si. Revela-se a inversão das raízes econômicas, deturpando a lógica produtiva a seu favor.

Todo esse jogo de manipulação requer estratégias para sua reprodução histórica. A ordem do capital posta pelos detentores dos meios de produção tem a subordinação como ingrediente sustentador. Os dominados são potencialmente revoltosos, devendo ser constantemente controlados. Além disso, entendida como fator de produção, a força do trabalho precisa ser verticalmente orientada à potencialização do mais-valor.

Com o capital erige-se uma estrutura de mando vertical, que instaurou uma divisão hierárquica do trabalho capaz de viabilizar o novo sistema de metabolismo social voltado para a necessidade da contínua, sistemática e crescente ampliação de valores de troca (idem: 537), no qual o trabalho deve subsumir-se realmente ao capital [...]. (ANTUNES, 2009, p. 23/4)

Essa sujeição se dá em diferentes níveis e suportes, atuando individualmente (e reciprocamente) na sociedade. A cisão do produzir, seu produto e fruição, fragmenta e ao mesmo tempo coisifica cada etapa. Do trabalho retalhado cria-se um Frankenstein social mistificado, inexorável devorador da essencialidade do humano.

Para entender o fenômeno do estranhamento, essencial retomar as categorias marxistas envolvidas no trabalho humano teleológico. Motor do salto ontológico, o trabalhar repercutiu no ser humano não só a consciência de si, mas fecunda a própria essencialidade da generidade humana. A manipulação finalisticamente orientada das cadeias naturais causais é ontologicamente definidora do ser social. Momento essencial nessa prática é o da objetivação, materialização de um ideal que se corporifica em produto. Ressalte-se que a projeção mental abstrata do artefato já envolve uma escolha de agir que será impressa indelevelmente no produto.

Nessa concepção, o trabalho revela seu valor como uma consciência criativa que controla a organicidade para um propósito útil. Reconhecer-se como agente dessa modificação é essencial para a conformação subjetiva de quem trabalha. A manipulação 
do trabalho possui, além de uma dimensão objetiva (produto), uma atuação marcante na autoimagem do trabalhador.

A base fundamental para a compreensão do que se pode entender como estranhamento do trabalho foi traçada por Marx nos textos de juventude que viriam a ser condensados sob o título de Manuscritos Econômico-Filosóficos. De fato, a questão, em última análise, se constitui enquanto problema filosófico, por dizer respeito a aspectos relativos à própria concepção do homem e de sua consciência como tais. Vale ressaltar que não vislumbramos ruptura essencial quanto à forma de compreensão que permeia estes escritos de sua juventude, se comparado com os de sua maturidade.

Para expor o que entende como estranhamento, Marx explicita seu ponto de partida em termos de recorte metodológico: "partimos dos pressupostos da economia nacional. [...] Supusemos a propriedade privada, a separação de trabalho, capital e terra, igualmente do salário, lucro de capital e renda da terra, da mesma forma que a divisão do trabalho [...]" (MARX, 2008, p. 79). Assim, deixa evidente que sua análise se refere, historicamente, às relações sociais que se desenrolam sob o modo de produção capitalista.

Para além do estranhamento ou exteriorização com relação ao produto objeto do trabalho humano (vale lembrar, como visto, que o ato de trabalhar envolve matizes de índole objetiva e subjetiva), Marx desvela também como se dá esse fenômeno de estranhamento relativamente ao processo produtivo em si. É justamente aí que reside a potencialidade da crítica filosófica ao modo de produção capitalista:

\begin{abstract}
Mas o estranhamento não se mostra somente no resultado, mas também, e principalmente, no ato da produção, dentro da própria atividade produtiva. Como poderia o trabalhador defrontar-se alheio (fremd) ao produto da sua atividade se no ato mesmo da produção ele não se estranhasse a si mesmo? [...] Em que consiste, então, a exteriorização (Entäusserung) do trabalho? Primeiro, que o trabalho é externo (äusserlich) ao trabalhador, isto é, não pertence ao seu ser, que ele não se afirma, portanto, em seu trabalho, mas nega-se nele, que não se sente bem, mas infeliz, que não desenvolve nenhuma energia física e espiritual livre, mas mortifica sua physis e arruína o seu espírito. [...] Igualmente, quando o trabalho estranhado reduz a autoatividade, a atividade livre, a um meio, ele faz da vida genérica do homem um meio de sua existência física. A consciência que o homem tem do seu género se transforma, portanto, mediante o estranhamento, de forma que a vida genérica se torna para ele um meio (MARX, 2008, pp. 82-85).
\end{abstract}

Parece-nos que a precisão do argumento se perfaz na medida em que, paradoxalmente (ou não), aponta para a existência de uma forte carga de subjetividade na objetivação. Se o que caracteriza o homem enquanto tal e enquanto ser social é sua 
capacidade de agir segundo a determinação prévia e consciente de finalidades, é justamente a inversão desta consciência que caracteriza a perversidade do processo de alienação ou estranhamento, ao anular aquilo que constitui nossa própria humanidade. A própria subjetividade do trabalhador é capturada como algo externo a si e, portanto, alheio.

Nessa dimensão subjetiva do pôr teleológico, Lukács desenvolve, a partir do aporte de Marx, a categoria da alienação (que, na realidade, é indissociavelmente vinculada a objetivação). O sujeito que trabalha modifica a si no momento em que adquire conhecimento, experimenta e manipula sensivelmente o real adquirindo experiência e saber (LUKÁCS, 2012, p. 302).

O produto do trabalho não é somente um objeto que se incorpora na sociedade, mas abrange a execução de uma atividade por um agente, indivíduo que na práxis empregou seu pensamento e corpo. Desenvolvem-se potencialidades e capacidades que tocam a subjetividade e semeiam a compreensão ontológica do homem como humano.

Para compreender a especificidade do ser social é preciso compreender e ter presente essa duplicidade: a simultânea dependência e independência de seus produtos e processos específicos em relação aos atos individuais que, no plano imediato, fazem com que eles surjam e prossigam (LUKÁCS, 2012, p. 240).

Entretanto, a inescapável interferência da sociedade na gestação de subjetividades envolve uma violência (às vezes materialmente externalizada) na medida em que conforma a atuação livre e individual para uma adaptação ao complexo social. Porém, a ascensão do capitalismo e da sua inerente propriedade privada incorporou nessa mediação uma interferência única.

A propriedade privada deturpa o fluxo produtivo, carregando no seu conceito de posse um caráter desumanizador do produto. A alienação subjetiva formadora da consciência social é mediada agora pela submissão ao capital burguês. O trabalhador submetido à lógica capitalista, ao ser alijado do seu produto de trabalho e dos meios de produzi-lo, se vê órfão de ferramentas essenciais para constituição de si e consequentemente de sua generidade humana.

Dá-se aqui o fenômeno do estranhamento, em que a legitimação da propriedade privada em verdade priva o trabalhador dos meios de produção em sentido amplo, como elementos formadores de sua subjetividade. Vital entender o caráter 
opressor desse estranhar que, em manifestação ubíqua, define quem se é e qual seu propósito no coletivo.

Estranhar-se, então, é afastar-se da sua essência individual e da consciência humana. Um estranhado é ex-cêntrico, distante do coração e cerne de sua atividade produtiva, perdendo o domínio sobre sua intencionalidade. Nas palavras de Marx, "[...] a atividade do trabalhador não é a sua auto-atividade. Ela pertence a outro, é a perda de si mesmo" (MARX, 2008, p. 83).

A força de trabalho é despersonificada e classificada como mercadoria do processo produtivo. A utilidade do homem é vinculada a sua capacidade de trabalho como propriedade privada capitalista. Verifica-se aqui a divergência entre desenvolvimento de capacidade individual como força de trabalho em contraponto com a formação da personalidade humana.

Inegável que a empreitada capitalista promoveu e aprimorou tecnologias importantes, elevando a potencialidade do trabalho a patamares altíssimos de resultado, leia-se lucro. Ao inserir a teleologia do capitalista no fazer do empregado, o trabalho explorado é o adicionar fermento vivo ao objeto morto. Essa vida manipulada pelo interesse do mais-valor é terra fértil para a prosperidade, uma máquina pronta a ser pilotada.

A dominação pelo estranhamento atua biopoliticamente 7 , gerando corpos dóceis, flexíveis e maleáveis aos intentos capitalistas. Entretanto, além da extrema seletividade no gozo dessa bonança, os custos humanos dessa dinâmica são os da completa anulação do indivíduo. Enxergar a degradação de personalidades humanas como mera contingência em favor do "progresso" gerou, historicamente, aberrações impensáveis.

Mas será que essa alienação obscurecida pelo estranhamento gera a mesma reação passiva em todos os explorados? Novamente, a análise histórica demonstra que há respostas insurgentes, tentativas de resistência e superação dos mecanismos opressores. Nessa esteira, destaca-se o papel fundamental e constante da subordinação para manter a roda do capital girando calcada na crença, individualmente compartilhada, de que a divisão social do trabalho vigente é natural.

O autoestranhamento não é fenômeno exclusivo do polo explorado da relação. $\mathrm{Na}$ verdade, todos estão envoltos na mitologia da essencialidade da propriedade

\footnotetext{
7 Conceito trabalhado em: FOUCAULT, 2012.
} 
privada, patrões e empregados. Todavia, o capitalista aufere o benefício dessa ordem enquanto os trabalhadores se veem pauperizados. Invariavelmente, os dois polos estão embebidos na privação da consciência humana advinda do trabalho teleológico.

Perceba-se que o estranhamento atua também na própria liberdade no momento do pôr-teleológico. Liberdade aqui é compreendida como a escolha dentre alternativas que efetivamente poderão dar-se na realidade. Optar por determinada finalidade para o satisfazer útil de uma necessidade. O véu do estranhamento defrauda o autoconhecimento no momento que enviesa a experiência humana a um propósito pré-determinado.

Quanto maior for o conhecimento das cadeias causais que operam em cada caso, tanto mais adequadamente elas poderão ser transformadas em cadeias causais postas, tanto maior será o domínio que o sujeito exerce sobre elas, ou seja, a liberdade que aqui ele pode alcançar (LUKÁCS, 2012, p. 103).

Compreensão parecida do fenômeno enxergada por Engels:

A liberdade não reside na tão sonhada independência em relação às leis da natureza, mas no conhecimento dessas leis e na possibilidade proporcionada por ele de fazer com que elas atuem, conforme um plano, em função de determinados fins. Isso vale tanto com referência às leis da natureza externa quanto àquelas que regulam a existência corporal e espiritual do próprio homem [...]. Em consequência, liberdade da vontade nada mais é que a capacidade de decidir com conhecimento de causa (ENGELS, 2015, p. 106).

As bases forjadoras e mantenedoras dessa submissão atuam em todas as esferas cotidianas. As regras dessa performance social são institucionalmente orquestradas, chancelando a manutenção do estranhamento como definidor do (sobre)viver. Portanto, resta mais do que escancarada a incompatibilidade entre o estranhamento que chancela a reprodução do capitalismo e a conquista da liberdade humana.

A superação da opressão somente acontecerá com a práxis transformadora no esteio da história, com o processo revolucionário de subversão da lógica que nos impele à venda do inalienável. Só então poderá o trabalho humano, material e coletivamente, libertar-se das amarras do estranhamento e da exploração. E esse processo revolucionário só pode se dar com e pelo trabalho, na busca de um conteúdo social emancipatório em que possa se manifestar enquanto atividade vital consciente e, portanto, verdadeira e substancialmente livre. 
A liberdade substancial pela qual se pugna aqui não se confunde, de forma alguma, com a ilusão de liberdade burguesa. Esta última se presta à abstração, ao forjamento de um espaço de sociabilidade que oculta a instância material e suas disputas concretas, além de se fundar na noção de liberdade em sentido individual, ao invés de fazê-lo no plano da luta coletiva. E "nas coisas deste mundo não é tão livre o homem [...]. [...] César e sua fortuna! - toda a sabedoria humana está contida nestas quatro palavras" (ASSIS, 1876, p. 66.)

\section{Considerações finais: por um conteúdo social emancipatório para o trabalho}

Ao resgatar a compreensão valorativa mais profunda acerca do que é o trabalho humano e de quais são seus possíveis sentidos, o artigo se propôs a expor que o conceito não pode ser reduzido a uma de suas múltiplas expressões. Do trabalho verdadeiramente livre, fundador da própria sociabilidade humana, ao trabalho estranhado e espoliado por um modo de produção que se reproduz a partir da extração de valor da força de trabalho alheia, muitos são os significados e as particularidades históricas que constituem esta categoria social.

Compreender a amplitude do conceito trabalho releva não só em termos teóricos, mas também e fundamentalmente em termos políticos. Isso porque toda teoria só pode ser emancipatória enquanto práxis, enquanto transformação do mundo. Assim, explorar as diversas facetas axiológicas e históricas da categoria trabalho não constitui mero preciosismo acadêmico, mas antes (e, sobretudo) arcabouço central para compreender nossos processos de resistência social à barbárie.

Se, como visto, a peculiaridade do estranhamento capitalista do trabalho reside em inverter a consciência para transformá-la em mera (tentativa de) sobrevivência, o trabalho estranhado poderia ser compreendido, bem dizer, como uma espécie de negação do trabalho verdadeiramente livre. Mas, se o sentido primeiro de trabalho nos remete à ideia de atividade vital consciente, como visto no item inicial deste artigo, qual o sentido, portanto, de chamar o trabalho estranhado de trabalho? 0 sentido é o de reforçar a centralidade da usurpação da atividade vital humana para a reprodução do modo de produção capitalista, e compreender que este processo se dá 
segundo particularidades históricas que, como particularidades que são, não são inevitáveis, sobrenaturais ou imodificáveis.

Abrir mão da categoria trabalho (seja para explicar o funcionamento do capitalismo, seja para nomear o mote do processo revolucionário que visa a sua superação) se configura enquanto uma solução reducionista que não dá conta da complexidade que esta categoria encerra. Simplesmente criar um novo conceito para aquilo que, substancialmente, nos caracteriza enquanto seres sociais, parece contribuir para nublar a possibilidade de visualizar outra forma de vida que não seja a regida pelo sistema capitalista. Parece contribuir para a naturalização de uma das múltiplas formas de expressão de um conceito que, antes de ser meramente teórico, é vital para a compreensão das relações sociais.

Parece-nos plausível recobrar, a esta altura, as duas crenças abordadas na introdução, que tendem a ignorar a multiplicidade de sentidos da categoria trabalho (e que, no fundo, compartilham de premissas similares), para pontuar suas fragilidades teórico-políticas e pugnar pela importância de uma compreensão ampliada da categoria trabalho. Não há qualquer pretensão exaustiva nos diagnósticos aqui apontados, mas, sim, um esforço investigativo acerca dos potenciais efeitos das escolhas discursivas que dispensam a centralidade da reivindicação do conteúdo social do trabalho em suas estratégias de luta.

Quanto à primeira crença, comum às teses de uma suposta tendência de fim da sociedade do trabalho, nota-se que tem servido de alicerce aos discursos hegemônicos que pautam as medidas contemporâneas de austeridade na negação da existência social do conflito capital-trabalho. Isto se deve ao fato de que, ao se negar a centralidade do trabalho enquanto categoria-chave de compreensão das relações sociais, torna-se muito mais palatável negar a existência da própria exploração em si.

Quanto à segunda, que denota uma opção epistemológica de se abrir mão do próprio conceito de trabalho enquanto fundamento do movimento revolucionário de superação do capitalismo, o resultado político é igualmente desastroso. Reduzir a expressão da categoria ao trabalho estranhado capitalista opera a naturalização desta forma de organização e de divisão social do trabalho. Implica retirar o conceito da história e, consequentemente, restringe as lentes pelas quais se pode pensar o horizonte de uma vida substancialmente livre e emancipada. 
É perceptível, portanto, a relevância primordial de se resgatar a base axiológica e histórica do próprio conceito de trabalho, em seus variados sentidos socialmente construídos, pois ignorá-la implica fortalecer a fragmentação política da classe trabalhadora e a desarticulação da luta coletiva (já tão aguçadas em tempos de aprofundamento desenfreado das disparidades do conflito capital-trabalho).

\section{Referências bibliográficas}

ALBORNOZ, Suzana. O que é trabalho. 3a ed. São Paulo: Brasiliense, 1988.

ANTUNES, Ricardo. Adeus ao trabalho? Ensaio sobre as metamorfoses e a centralidade do mundo do trabalho. 11a ed. São Paulo: Cortez; Campinas: Ed. da Universidade Estadual de Campinas, 2006.

ANTUNES, Ricardo. Os Sentidos do trabalho: ensaio sobre a afirmação e a negação do trabalho. 2ª ed. São Paulo: Boitempo, 2009.

ARENDT, Hannah. A condição humana. Tradução de Roberto Raposo. 10ạ ed. Rio de Janeiro: Forense Universitária, 2007.

ASSIS, Machado de. Helena. 1876. Disponível em: <http://www.dominiopublico.gov.br/pesquisa/DetalheObraForm.do?select_acti on=\&co_obra=2091>. Acesso em: 10 jan. 2020.

COELHO, Bruna da Penha de Mendonça. O samba carioca e a centralidade do trabalho vivo: Poetas operários. Curitiba: Juruá, 2019.

DAL ROSSO, Sadi. Mais trabalho! A intensificação do labor na sociedade contemporânea. São Paulo: Boitempo, 2008.

ENGELS, Friedrich. Anti-Duhring: A revolução da ciência segundo o senhor Eugen Dühring. Tradução de Nélio Schneider. São Paulo: Boitempo, 2015.

FONTES, Virgínia. O Brasil e o Capital-Imperialismo: Teoria e história. 2ª ed. Rio de Janeiro: Editora UFRJ, 2010.

FOUCAULT, Michel. História da sexualidade I: A vontade de saber. 22a reimpressão. Tradução de Maria Thereza da Costa Albuquerque e José Augusto Guilhon Albuquerque. Rio de Janeiro: Edições Graal, 2012.

FREIRE, Paulo. Pedagogia do oprimido. 69a ed. Rio de Janeiro: Paz e Terra, 2019. 
HABERMAS, Juergen. A nova intransparência: a crise do estado de bem-estar social e o esgotamento das energias utópicas. Tradução de Carlos Alberto Marques Novaes. Revista Novos Estudos, 18 ed., vol. 2, setembro de 1987.

HEGEL, Georg Wilhelm Friedrich. Fenomenologia do Espírito. 4ạ ed. Tradução de Paulo Meneses. Rio de Janeiro: Vozes, 2014.

LESSA, Sergio. Lukács: trabalho, objetivação, alienação. Trans/Form/Ação, São Paulo, v. 15, 1992. Disponível em: <http://www.scielo.br/scielo.php?script=sci_arttext\&pid=S010131731992000100002>. Acesso em: 20 de nov. de 2019.

LESSA, Sergio. Para compreender a Ontologia de Lukács. 4ạ ed. São Paulo: Instituto Lukács, 2015.

LUKÁCS, György. Para uma ontologia do ser social 1. Tradução de Carlos Nelson Coutinho, Lya Luft, Mario Duayer, Nélio Schneider e Rodnei Antônio do Nascimento. São Paulo: Boitempo, 2012.

MAGALHÃES, Theresa Calvet de. A Atividade Humana do Trabalho [Labor] em Hannah Arendt. Disponivel em: <http://www.ufjf.br/eticaefilosofia/files/2010/03/9_1_theresa.pdf>. Acesso em: 09 jan. 2020.

MARX, Karl. Manuscritos econômico-filosóficos. Tradução de Jesus Ranieri. São Paulo: Boitempo, 2008.

MARX, Karl. O Capital: Crítica da economia política. Livro I: O processo de produção do capital. Tradução de Rubens Enderle. 2a ed. São Paulo: Boitempo, 2011.

MARX, Karl. O Capital: Crítica da economia política. Livro III: O processo global da produção capitalista. Tomo II. Tradução de Regis Barbosa e Flávio R. Kothe. 2a ed. São Paulo: Nova Cultural, 1985/6.

MARX, Karl; ENGELS, Friedrich. A ideologia alemã: Crítica da mais recente filosofia alemã em seus representantes Feuerbach, B. Bauer e Stirner, e do socialismo alemão em seus diferentes profetas. Tradução de Rubens Enderle, Nélio Schneider e Luciano Cavini Martorano. São Paulo: Boitempo, 2007.

MATOS, Felipe de Souza. Manda quem pode, obedece quem precisa: Atualidade e centralidade da subordinação laboral para o capitalismo. Trabalho de conclusão de curso. Faculdade Nacional de Direito - UFRJ. Orientadora: Bruna da Penha de Mendonça Coelho. Rio de Janeiro, 2019. 
OFFE, Claus. Trabalho: a categoria-chave da sociologia? Disponível em: <http://www.anpocs.org.br/portal/publicacoes/rbcs_00_10/rbcs10_01.htm>. Acesso em 24 jun. 2018. In Disorganized Capitalism: contemporary transformations of work and politics. Oxford, Basil Blackwell, 1986. Traduzido do inglês por Lucia Hippolito.

OLIVEIRA, Avelino da Rosa. O problema da liberdade no pensamento de Karl Marx. PERSPECTIVA. Florianópolis, v. 16, n. 29, jan./jun. 1998. Disponível em: <https://periodicos.ufsc.br/index.php/perspectiva/article/download/10638/101 71>. Acesso em: 13 de jun. de 2019.

PEIXOTO, Elza Margarida de Mendonça. Marxismo, educação e emancipação humana. Germinal: Marxismo e Educação em Debate, Salvador, v. 5, n.1, p. 5-28, jun. 2013.2 Disponível em: <https://portalseer.ufba.br/index.php/revistagerminal/article/view/9632/7046>. Acesso em: 10 jan. 2020.

PRIEB, Sérgio. Os efeitos da crise econômica sobre a classe trabalhadora. Disponível em: <http://www.revistaovies.com/artigos/2012/05/os-efeitos-dacrise-economica-sobre-a-classe-trabalhadora/>. Acesso em: 07 jul. 2018.

RANIERI, Jesus. Alienação e estranhamento: a atualidade de Marx na crítica contemporânea do capital. III Conferencia Internacional La Obra de Carlos Marx y los desafíos del Siglo XXI, 2006. P. 1. Disponível em: <https://www.nodo50.org/cubasigloXXI/congreso06/conf3_ranieri.pdf>. Acesso em: 9 jan. 2020.

SMITH, Adam. A Teoria dos Sentimentos Morais. Tradução de Lya Luft. São Paulo: Martins Fontes, 2002.

Sobre os autores

Bruna da Penha de Mendonça Coelho

Doutoranda em Teoria e Filosofia do Direito (PPGD/UERJ) e em Sociologia (Instituto de Estudos Sociais e Políticos da UERJ - Bolsista CNPq). Mestra em Teoria e Filosofia do Direito pelo PPGD/UERJ. Graduada em Direito pela UERJ. E-mail: brunapmcoelho@gmail.com. ORCID: https://orcid.org/0000-0003-4974-1590.

\section{Felipe de Souza Matos}

Graduado em Direito pela Faculdade Nacional de Direito (UFRJ). Técnico Judiciário do TRT1. E-mail: felipematos14@hotmail.com. ORCID: https://orcid.org/0000-00019618-5430.

Os autores contribuíram igualmente para a redação do artigo. 